\title{
Joint Modeling of Poverty of Households and Malnutrition of Children Under Five Years from Demographic and Health Survey Data: Case of Rwanda
}

\author{
Faustin Habyarimana*, Temesgen Zewotir, Shaun Ramroop \\ University of KwaZulu-Natal, South Africa \\ singizwabb@gmail.com
}

\begin{abstract}
The main objective of this study was to identify the risk factors associated to malnutrition of children under five years and poverty and assess the correlation between them. We created a composite index from three anthropometric indictors (stunting, underweight and wasting).A multivariate joint model using the generalized linear mixed model was utilized for the analyses of the data. Child age, birth order of the children, the gender of children, birth weights of the children, multiple birth of the child, fever, anemia of the mother, body mass index of the mother, mother's education level, mother's knowledge on nutrition, age of household head, source of drinking water, toilet facilities, place of residence of household, source of drinking water and province were found to be significantly related to poverty and malnutrition. The study revealed a positive correlation between poverty of household and malnutrition of children less than five years
\end{abstract}

Keywords: Asset index, composite index, DHS, correlation

\section{Introduction}

Malnutrition of children under five years and poverty of households are among the main problems faced mostly by developing countries(Demissie \& Worku, 2013). Malnutrition is the main cause of morbidity and mortality of children under five years. Malnutrition is responsible for at least half of all childhood death worldwide (Kavosi et al., 2014; Demissie \& Worku, 2013; Heinkens et al., 2008; Nandy et al., 2005).The nutritional status of the children can be used as an indicator of health problem in developing countries (Masibo \& Makoka, 2012). Malnutrition of children under five years is commonly measured based on three anthropometric indicators known as stunting or insufficient height-for-age which indicates chronic or longterm malnutrition, wasting or insufficient weight-for-height which represents a failure to receive adequate food intake or a recent period of illness causing the loss of weight, and underweight or insufficient weightfor-age which is the composite index of wasting and stunting (WHO, 1995). If anthropometric measurements are taken regularly over time, they can offer information on how the health status of the population, especially of children, is changing and provide a timely warning on the food supply and poverty status. When the objective of the study is to obtain a quick picture of a community or large body of population to understand the extent of the problem, the measurement of wasting alone would provide sufficient information. However, if the purpose is to obtain information to decide what types of programs are needed in the specific region, the study can involve all three indexes of anthropometric measurements (Setboonsarng, 2005 ) or the joint model of all three anthropometric indices. But if the need is to identify the risk factors associated to malnutrition and poverty of households, a composite index of malnutrition is needed. These three anthropometric variables are measured through z-scores for height-for-age (stunting), weight-forheight (wasting) and weight-for-age (underweight) and are defined as

$Z_{i}=\frac{A I_{i}-\mu}{\sigma}$

Where $A I_{i}$ is the individual (child) anthropometric indicator, $\mu$ and $\sigma$ refer respectively to median and standard deviation of the reference population. The higher the value of z-score the better the nutrition status of the child. Usually, these anthropometric indicators are used separately (Justice et al., 2015; Habyarimana et al., 2014; Matanda et al., 2014; Islam et al., 2013; Kandala et al., 2011; Das \& Rahman, 2011) to identify the factors associated to the malnutrition of children or jointly (Habyarimana et al., 2015d; 2015e). In many researches poverty index is used as an explanatory variable for malnutrition (Kandala et al., 2011; Habyarimana et al., 2015d) among others. 
After rigorous reading, we found no study in literature using DHS data to find a single composite index of three anthropometric indices and thereafter jointly identify the correlation between malnutrition of children less than five years and poverty of household as well as the factors associated with them. Therefore, the current study focuses on creating a single composite index from the classical anthropometric indices. Thereafter the study jointly identifies the risk factors associated with poverty and malnutrition of children less than five years and it finally assess the possible correlation between them.

Source of data: The Rwanda Demographic and Health Survey data (2010) was used in the current research where the sampling technique was done in two-stage stratified sampling. In the first stage 492 villages also known as clusters were selected with probability proportional to the number of households residing in that village, 12540 households, where 2009 and 10531 households were urban and rural respectively. Secondly, systematic sampling was used to all households existing in the selected villages(NISR et al., 2012). RDHS (2010) collected information on men and women aged 15-49 and 4,356 children under five years old. We have used the household characteristics, demographic characteristics, child's characteristics, mother's characteristics, environmental characteristics and health characteristics.

\section{Methodology}

Principal component analysis: Principal component analysis (PCA) is a multivariate statistical technique that linearly transforms an original data set of variables into a substantially smaller set of uncorrelated variables that represent most of the information in the original set of variables (Jackson, 2005; Manly, 2004; Jolliffe, 2002; Lewis-Beck, 1994). Let us consider $X_{1}, X_{2}, \ldots, X_{k}$, as malnutrition indicators, the main objective of the PCA is to take these $\mathrm{k}$ malnutrition indicator variables and find their combination to produce indices $Z_{1}, Z_{2}, \ldots, Z_{k}$ that are not correlated and whose variances decrease from first to last (Chatfield \& Collins, 1980); the $Z_{k}$ indices produced are then the principal components given by

$Z_{k}=a_{k 1} X_{1}+a_{k 2} X_{2}+\cdots+a_{k k} X_{k}=a_{k}^{T} X$

Where $a_{k}^{T}=\left[a_{1 k}, a_{2 k}, \ldots, a_{k k}\right]$ are vectors of the scoring factors or weights. The coefficients of principal components are chosen such that the first component $Z_{1}$ accounts for as much of the variation in the original data as possible subjected to the constraint that the sum of the squares of the scoring factors (or weights) is equal to 1 . The second component is completely uncorrelated with the first component, and explains additional but less variation than the first component, subject to the same constraint of the sum of the squares of the scoring factors equal to 1 . The subsequent components are uncorrelated with the previous components; therefore each component captures an additional dimension in the data, while explaining smaller and smaller proportions of the variation of original variables in the data. The remaining components are computed in a similar fashion. Kaiser's rule (Kaiser-Guttman rule) is the commonly most used criterion for deciding the number of components to be retained. This criterion retains only those components whose eigenvalues are greater than 1.00; the graphical method called a scree diagram is also used when deciding the number of component to be retained; Kaiser-Meyer-Olkin (KMO) is also the most used criterion for measuring sampling adequacy. This criterion compares the magnitude of the observed correlation to the magnitude of the partial correlation coefficient. The Bartlett's test criterion is also used to test if there is a certain redundancy between the variables. We have used SPSS 22 in the computation of the composite index and the results are presented in Figure 1, Table 1 and Table 2. 
Figure 1: Scree plot test

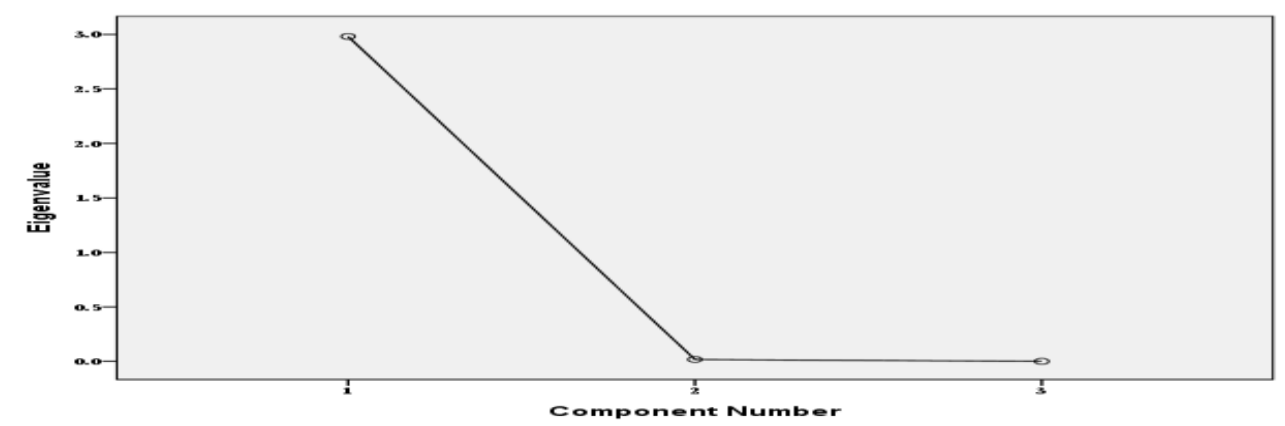

Table1: Total variance explained

\begin{tabular}{llll}
\hline component & Total & \% variance & Cumulative \% \\
\hline 1 & 2.983 & 99.386 & 99.386 \\
2 & 0.989 & 0.598 & 99.984 \\
3 & 0.000 & 0.160 & 100.00 \\
\hline
\end{tabular}

Table 2: KMO and Bartlett's test

\begin{tabular}{ll}
\hline KMO measure of sampling adequacy & .534 \\
Bartlett's test of approximate chi-square & 43459.952 \\
Df & 3 \\
Significance & $<.0001$ \\
\hline
\end{tabular}

It is observed from Table 1 that the first component alone explains $99.386 \%$ of the total variation of all anthropometric indices and this is excellent. Table 2 presents Kaiser-Meyer-Olkin (KMO) measure of sampling adequacy and Bartlett's test of sphericity which is significant. It is observed from the scree plot test Figure 1 that the first component suffices to explain the total variation of the original data. Therefore, based on these tests and the results from Table1, we used first component as the new composite index of malnutrition. Further it was classified as nutrition status (malnourished if $\mathrm{z}$-score $<-2.0$ and nourished if $\mathrm{z}$ score $\geq-2.0$ ) and transformed and re-coded into binary outcome. In this study, in the case of poverty, we used the results from Habyarimana et al. (2015a), Habyarimana et al. (2015b) and Habyarimana et al. (2015c) where they created an asset index based on principal component analysis and classified each household included in the survey as poor or not poor; and this classification made the outcome variable to be binary .

Model overview: Let us consider $y_{i 1}$ to be child nutrition status ( 1 malnourished case or 0 nourished cases) and $y_{i 2}$ to be the socio-economic status of the household ( 1 if the household is poor and 0 otherwise). Let us consider that the observed outcomes arise from a bivariate Bernoulli distribution, with $p_{i 1}$ as the probability of malnutrition occurring in child $i$ and $p_{i 2}$ as probability of poverty of household $\mathrm{i}$. Therefore, the binary generalized linear model can be formulated as follows

$g_{1}\left(\mu_{\mathrm{i} 1}\right)=\mathrm{X}_{\mathrm{i} 1} \beta_{1}+\mathrm{Z}_{\mathrm{i} 1} \mathrm{u}_{1}$

$$
g_{2}\left(\mu_{\mathrm{i} 2}\right)=\mathrm{X}_{\mathrm{i} 2} \beta_{2}+\mathrm{Z}_{\mathrm{i} 2} \mathrm{u}_{2}(4)
$$

Where $\beta_{1}$ and $\beta_{2}$ are vectors of fixed effects and $u_{1}$ and $u_{2}$ are the vectors of the random effects, $X_{i 1}, X_{i 2}, Z_{i 1}$ and $\mathrm{Z}_{\mathrm{i} 2}$ are the designs matrices for fixed effects and random effects respectively.

$\mathrm{u}=\left(\begin{array}{l}u_{1} \\ u_{2}\end{array}\right) \sim$ i. i. d. $\operatorname{MVN}(0, \Sigma)=\operatorname{MVN}\left(\left[\begin{array}{l}0 \\ 0\end{array}\right],\left[\begin{array}{ll}\sum_{11} & \sum_{12} \\ \sum_{21} & \sum_{22}\end{array}\right]\right)(5)$

Where equation (5) is the variance-covariance matrices of the joint model, $\sum_{11}, \sum_{22}$, are the variance components of malnutrition of children under five years and poverty of households respectively. $\sum_{12}=$ $\sum_{21}$ Are the correlation components between malnutrition and poverty. If $\sum_{12}=\sum_{21}=0$, then the above model is equivalent to separate generalized linear mixed models for two outcome variables. The multivariate joint model under generalized linear mixed model has advantages over the separate models such as better control of type I error rates in multiple test, the possible gain in efficiency in the parameter estimate and also the ability to answer intrinsically multivariate questions (Gueorguieva, 2001; Molenberghs \& Verbeke, 2005). 
Analysis: Data analysis was done using SAS 9.3 PROC GLIMMIX procedure. It allows to jointly modeling two outcomes with the same distributions or the same link functions or different link functions. In this study same distributions and same link functions are considered for both outcome variables. We have considered various covariance structures, but based on the convergence criteria Unstructured (UN) covariance structure was found to be suitable to the analysis. Also due to a lower AIC, we have also checked for possible interaction effect but none was significant.

\section{Results and Interpretations}

The findings of this study revealed a significant positive correlation between poverty of household and malnutrition of children less than five years Table 4 . This means that poverty and malnutrition change in the same direction; when the poverty of household increases malnutrition of children less than five years in that household also increases, or in contrast, when the poverty of household reduces, in general malnutrition also reduces. The results of factors associated to malnutrition are presented in Table 3. From the same table, it is observed that mother's level of education significantly affects nutrition status of the child as well as the socioeconomic of the household. The malnutrition of children under five years and poverty of household reduce with increasing the mother's level of education. The age of the child significantly affects the child's nutrition status. A child aged between 12 and 23 months is 0.5689 (p-value=0.0049) times less likely to be malnourished than infant (0-11 months). The birth order of the child positively affects malnutrition of the child. A first born child is 0.4742 ( $\mathrm{p}$-value<.0001) times less likely to be malnourished than a sixth born child or those born thereafter. The gender of the child is found to significantly affect the nutrition status of the child. A male child is 1.6242 (p-value<.0001) times more likely to be malnourished than a female child. Birth weight significantly affects the child's nutrition status. A child born with a higher weight (weight $\geq 2500 \mathrm{~g}$ ) is 0.3128 ( $p$-value <.0001) times less likely to be malnourished than a child born with lower weight (weight< 2500g).

The mother's knowledge on nutrition also significantly affects the child's nutrition status. A child born to mother with some knowledge of nutrition is 0.6880 ( $p$-value=0.0036) times less likely to be malnourished than a child born to mother without knowledge on nutrition. Multiple births significantly affect the children's nutrition status. A child born singleton is 0.3712 ( $p$-value=0.0317) times less likely to be malnourished than a child born second multiple or more. The incidence of anemia of the mother significantly affects the nutrition status of the child. A child born to anemic mother is 1.3661 (p-value $=0.0088$ ) times more likely to be malnourished than a child born to a non-anemic mother. The incidence of fever is also seen to significantly affect the nutrition status of the child. A child who did not have fever during the two weeks before the survey is 0.6623 ( $p$-value $=0.0043$ ) times less likely to be malnourished as compared to a child who was reported to have had a fever in the two weeks prior to the survey. The place of residence of household significantly affects socio-economic status of household. An urban household is 0.7718 (p-value <.0001) times less likely to be poor than a rural household. The province significantly affects the socio-economic status of the household. It was found that a household from Western, Northern and Eastern province is 15.7053 (p-value <.0001), 7.8853 (p-value <.0001) and 3.5715 (p-value <.0001) respectively poorer as compared to a household from Kigali city. A child born to normal or obese mother (BMI $\geq 18.5$ ) is 0.3723 (p-value <.0001) times less likely to be malnourished than a child born to underweight mother. This result shows that there is a strong association between weight of the mother and nutrition status of the child.

Table 3: Parameter estimates for a joint model of malnutrition and poverty

\begin{tabular}{|c|c|c|c|c|c|c|c|c|}
\hline & \multicolumn{4}{|c|}{ Malnutrition } & \multicolumn{4}{|c|}{ Poverty of households } \\
\hline Indicator variable & Estimate & $\mathrm{SE}$ & $p$-value & OR & Estimate & SE & $\mathrm{p}$-value & OR \\
\hline Intercept & 2.878 & 1.420 & 0.043 & 17.7787 & -0.564 & 0.200 & 0.0049 & 0.5689 \\
\hline \multicolumn{9}{|c|}{ Child's age (ref=0-11 months) } \\
\hline $12-23$ months & -0.564 & 0.200 & 0.0049 & 0.5689 & 0.344 & 0.215 & 0.1097 & 1.4106 \\
\hline $24+$ months & -0.167 & 0.129 & 0.1928 & 0.8462 & 0.002 & 0.148 & 0.9818 & 1.0020 \\
\hline \multicolumn{9}{|c|}{ Birth order (ref $=6$ and more) } \\
\hline $4-5$ orders & -0.108 & 0.160 & 0.5007 & 0.8976 & -0.085 & 0.199 & 0.6702 & 0.9185 \\
\hline $2-3$ orders & -0.213 & 0.171 & 0.2122 & 0.8081 & -0.188 & 0.204 & 0.3588 & 0.8286 \\
\hline $1^{\text {st }}$ order & -0.746 & 0.187 & $<.0001$ & 0.4743 & -0.139 & 0.212 & 0.5105 & 0.8702 \\
\hline
\end{tabular}




\begin{tabular}{|c|c|c|c|c|c|c|c|c|}
\hline \multicolumn{5}{|c|}{$\begin{array}{l}\text { Malnutrition } \\
\end{array}$} & \multicolumn{4}{|c|}{ Poverty of households } \\
\hline \multicolumn{9}{|c|}{ Mother's education (ref=secondary school and higher) } \\
\hline Primary & 1.678 & 0.400 & $<.0001$ & 5.3548 & 1.479 & 0.357 & $<.0001$ & 4.3885 \\
\hline No education & 1.788 & 0.413 & $<.0001$ & 5.9775 & 1.612 & 0.383 & $<.0001$ & 5.0128 \\
\hline \multicolumn{9}{|c|}{ Gender of the child (ref=Female) } \\
\hline Male & 0.485 & 0.116 & $<.0001$ & 1.6242 & -0.029 & 0.128 & 0.8219 & 0.9714 \\
\hline \multicolumn{9}{|c|}{ Birth weight (ref= $\geq 2500 \mathrm{~g}$ ) } \\
\hline$<2500 \mathrm{~g}$ & 1.400 & 0.448 & 0.0018 & 4.0552 & 1.151 & 0.2095 & $<.0001$ & 3.1613 \\
\hline \multicolumn{9}{|l|}{ Province (ref=Kigali) } \\
\hline South & 0.036 & 0.313 & 0.9073 & 1.0366 & -0.264 & 0.667 & 0.6929 & 0.7680 \\
\hline West & 0.060 & 0.170 & 0.7198 & 1.0618 & 2.754 & 0.301 & $<.0001$ & 15.784 \\
\hline North & -0.225 & 0.180 & 0.2132 & 0.7985 & 2.065 & 0.300 & $<.0001$ & 7.8853 \\
\hline East & -0.343 & 0.209 & 0.0997 & 0.7096 & 1.273 & 0.328 & $<.0001$ & 3.5715 \\
\hline \multicolumn{9}{|c|}{ Knowledge of nutrition $(\mathrm{ref}=\mathrm{no})$} \\
\hline Yes & -0.374 & 0.129 & 0.0036 & 0.6880 & -0.246 & 0.148 & 0.0969 & 0.7819 \\
\hline \multicolumn{9}{|c|}{ Multiple birth ( $\mathrm{ref}=2^{\text {nd }}$ and more $)$} \\
\hline First multiple & -0.350 & 0.609 & 0.5657 & 0.7047 & -0.655 & 0.839 & 0.4355 & 0.5194 \\
\hline Singleton & -0.991 & 0.461 & 0.0317 & 0.3712 & -0.815 & 0.691 & 0.2386 & 0.4426 \\
\hline \multicolumn{9}{|c|}{ Incidence of anemia (ref=non-anemic) } \\
\hline Anemic & 0.312 & 0.119 & 0.0088 & 0.312 & 0.260 & 0.138 & 0.0596 & 1.2969 \\
\hline \multicolumn{9}{|c|}{ Place of residence (ref=rural) } \\
\hline Urban & -0.259 & 0.278 & 0.352 & 0.7718 & -2.530 & 0.503 & $<.0001$ & 0.0796 \\
\hline $\begin{array}{l}\text { Age of household head } \\
\text { BMI (ref=BMI< 18.5) }\end{array}$ & 0.016 & 0.005 & 0.0027 & 1.0161 & 0.007 & 0.006 & 0.2271 & 1.0070 \\
\hline $\mathrm{BMI} \geq 18.5$ & -0.988 & 0.221 & $<.0001$ & 0.3723 & 0.374 & 0.303 & 0.217 & 1.4535 \\
\hline \multicolumn{9}{|c|}{ Incidence of Fever (ref=had fever last two weeks) } \\
\hline Had fever & -0.412 & 0.144 & 0.0043 & 0.6623 & 0.132 & 0.171 & 0.4401 & 1.1411 \\
\hline \multicolumn{9}{|c|}{ Source of drinking water (ref=other source) } \\
\hline Piped into dwelling & -0.318 & 0.419 & 0.446 & 0.7276 & 0.531 & 0.624 & 0.3951 & 1.7006 \\
\hline Public tap & 1.531 & 0.807 & 0.1384 & 4.6228 & -5.282 & 0.2 .682 & 0.049 & 0.0051 \\
\hline Protected spring & 0.865 & 0.584 & 0.1384 & 2.3750 & -0.051 & 0.850 & 0.9518 & 0.9503 \\
\hline \multicolumn{9}{|c|}{ Toilet facilities (ref=other toilets) } \\
\hline Latrine & -0.318 & 0.419 & 0.4482 & 0.7276 & 0.59 & 0.620 & 0.3416 & 1.8040 \\
\hline Ventilated & 1.541 & 0.807 & 0.0561 & 4.6692 & -5.268 & 2.612 & 0.0438 & 0.0051 \\
\hline Flushed & 0.870 & 0.584 & 0.1364 & 2.3869 & 0.093 & 0.849 & 0.9131 & 1.0975 \\
\hline \multicolumn{9}{|c|}{ Table 4: Variance Componen } \\
\hline \multirow{2}{*}{\multicolumn{5}{|c|}{$\begin{array}{l}\text { Label } \\
\text { Variance (Malnutrition) }\end{array}$}} & Estimate & SE & P-value & \\
\hline & & & & & 0.223 & 0.124 & 0.0362 & \\
\hline & 2.403 & 0.395 & $<.0001$ & \\
\hline \multicolumn{5}{|c|}{ Correlation between malnutrition and poverty of household } & 0.417 & 0.191 & 0.0293 & \\
\hline
\end{tabular}

Discussion: This study, based on principal component analysis technique created a composite index of malnutrition. Thereafter, a multivariate joint model under the generalized linear mixed model was used for the analyses of the data. This model has a number of advantages over the separate models; these are, among others, better control of type I error rates in multiple tests, the possible gain in efficiency in the parameter estimate and also the ability to answer intrinsically multivariate questions (Gueorguieva, 2001; Molenberghs \& Verbeke, 2005). The new composite index has advantages as well as limitations. This index can produce almost a similar subset of factors associated with malnutrition as the joint modeling of three anthropometric indices; it is not time consuming for convergence and it can help to simultaneously identify the factors associated with malnutrition and poverty of households as well as the correlation between them. However, if the need is to identify the risk factors associated to a specific type and level of malnutrition, a separate model of three anthropometric indices may be more helpful. 


\section{Conclusion}

Based on composite index of classical anthropometric indicators and joint modeling of poverty and malnutrition of children under five years of age, this study revealed a positive correlation between poverty of household and malnutrition of children less than five years. This means that malnutrition of children less than five years of age and poverty of household increase or decrease in the same direction. This suggests that any policy change made to poverty also affects malnutrition. The study also identified the risk factors associated to malnutrition of children under five years and poverty of households in Rwanda. The results showed that child's age, birth order of the child, gender of the child, birth weight of the child, multiple birth of the child, the incidence of fever, incidence of anemia of the mother, body mass index of the mother, province, place of residence, source of drinking water, toilet facilities, age of the household head, mother's education level and mother's knowledge on nutrition are the key determinants of malnutrition of children under five years of age and poverty of household. These findings are consistent with other researchers such as Kandala et al. (2011), Habyarimana et al. (2014), Habyarimana et al. (2015d), Justice et al. (2015) and Laghari et al. (2015).

Recommendations: To the policy makers and NGOs: in order to fight malnutrition of children under five years it should be worthwhile to also fight poverty of households. Improving nutrition status of the mother and her knowledge on nutrition can also help to reduce malnutrition of children less than five years. Improving the level of education of the mother can at the same time help to reduce poverty of households and malnutrition of children less than five years.

Acknowledgements: The authors acknowledge National Institute of Statistics of Rwanda (NISR) [Rwanda], Ministry of Health (MOH) [Rwanda], ICF International for data, Rwanda Education Board (REB) and University of Rwanda-College of Education (UR-CE) for financial support.

\section{References}

Chatfield, C. \& Collins, A. (1980). Introduction to multivariate analysis. London: Chapman and Hall.

Das, S. \& Rahman, R. M. (2011). Application of ordinal logistic regression analysis in determining risk factors of child malnutrition in Bangladesh. Nutrition journal, 10(1), 124.

Demissie, S. \& Worku, A. (2013). Magnitude and factors associated with malnutrition in children 6-59 months of age in pastoral community of Dollo Ado district, Somali region, Ethiopia. Scince Journal of Public Health,1(4), 175-183.

Gueorguieva, R. (2001). A multivariate generalized linear mixed model for joint modelling of clustered outcomes in the exponential family. Statistical Modelling, 1(3), 177-193.

Habyarimana, F., Zewotir, T. \& Ramroop, S. (2015e). Spatial distribution of key determinants of malnutrition of children under five years in Rwanda: Simultaneous measurements of three anthropometric indices. Under review.

Habyarimana, F., Zewotir, T. \& Ramroop, S. (2015d). Key determinants of malnutrition of children under five years in Rwanda: Simultaneous measurement of three anthropometric indices. Under review.

Habyarimana, F., Zewotir, T. \& Ramroop, S. (2015c). Determinants of poverty of households: Semiparametric analysis of demographic and health survey data from Rwanda. Journal of Economics and behavioural Studies, 7(3), 47-55.

Habyarimana, F., Zewotir, T. \& Ramroop, S. (2015b). Determinants of poverty of households in Rwanda: An application of quantile regression. Journal of Human Ecology, 50(1), 19-30.

Habyarimana, F., Zewotir, T. \& Ramroop, S. (2015a). Analysis of demographic and health survey data to measure poverty of household in Rwanda. African Population Studies, 29(1), 1472-1482.

Habyarimana, F., Zewotir, T. \& Ramroop, S. (2014). A Proportional Odds Model with Complex Sampling Design to Identify Key Determinants of Malnutrition of Children under Five Years in Rwanda. Mediterranean Journal of Social Sciences, 5(23), 1642-1648.

Heinkens, G. T., Bunn, B. J., Amadi, B., Manary, M., Chhagan, M., Brkley, J. A., Rollins, N., Kelly, P., Adamczick, C., Maitland, K. \& Tomkins, A. (2008). Case management of HIV-infected severely malnourished children: challenges in the area of highest prevalence. The Lancet, 371(2),1305-1307. 
Islam, M. M., Alam, M., Tariquzaman, M., Kabir, M. A., Pervin, R., Begum, M. \& Khan, M. M. H. (2013). Predictors of the number of under-five malnourished children in Bangladesh: application of the generalized poisson regression model. BMC public health, 13(1), 11.

Jackson, J. E. (2005). A user's guide to principal components. John Wiley \& Sons.

Jolliffe, I. T. (2002). Principal component analysis. Springer-Verlag.

Justice, M. K. A., Thomas, J. K., Benjamin, M. T. \& Petter, J. D. (2015). Childhood malnutrition and its determinants among uner-five children in Ghana. Paediatric and Perinatal Epidemiology, 29(6),552561.

Kandala, N. B., Madungu, T. P., Emina, J. B., Nzita, K. P. \& Cappuccio, F. P. (2011). Malnutrition among children under the age of five in the Democratic Republic of Congo (DRC): does geographic location matter? BMC public health, 11(1), 261-266.

Kavosi, E., Hassanzadeh, R. Z., Kavosi, Z., Nasihatkon, A., Moghadam, M. \& Heidari, M. (2014). Prevalence and determinants of under-nutrition among children under six: a cross-sectional survey in Fars province, Iran. Int J Health Policy Manag, 3(2), 71-76.

Laghari, Z. A., Soomro, A. M., Tunio, S. A., Lashari, K., Baloach, F. G., Baig, N. M. \& Bano, S. (2015). Malnutrition among children under five years in district Sanghar, Sindh, Pakistan. Gomal Journal of Medical Sciences, 13(1), 54-57.

Lewis-Beck, M. S. (1994). Factor analysis and related techniques. New London: Sage publication.

Manly, B. F. (2004). Multivariate statistical methods: a primer: CRC Press.

Masibo, P. K. \& Makoka, D. (2012). Trends and determinants of undernutrition among young Kenyan children: Kenya Demographic and Health survey: 1993, 1998, 2003 and 2008-2009. Public health nutrition, 15(9), 1715-1722.

Matanda, D. J., Mittelmark, M. B. \& Kigaru, D. M. D. (2014). Child undernutrition in Kenya: trend analyses from 1993 to 2008-2009. BMC pediatrics, 14(1), 5.

Molenberghs, G. \& Vebeke, G. (2005). Models for discrete longitudinal data. New York: Springer-Verlag.

Nandy, S., Irving, M., Gordon, D., Subramanian, S. V. \& Smith, G. D. (2005). Poverty and morbidity: new evidence from India. Bulletin of the World Health Organisation, 83(3),210-216.

NISR, ICF \& MoH (2012). Rwanda Demographic and Health Survey 2010, NISR.

Setboonsarng, S. (2005). Child malnutrition as a poverty indicator: An evaluation in the context of different development interventions in Indonesia: ADB Institute Discussion Papers.

WHO. (1995). Physical Status: the Use and Interpretation of Anthropometry:Report of a WHO Expert Committe. 